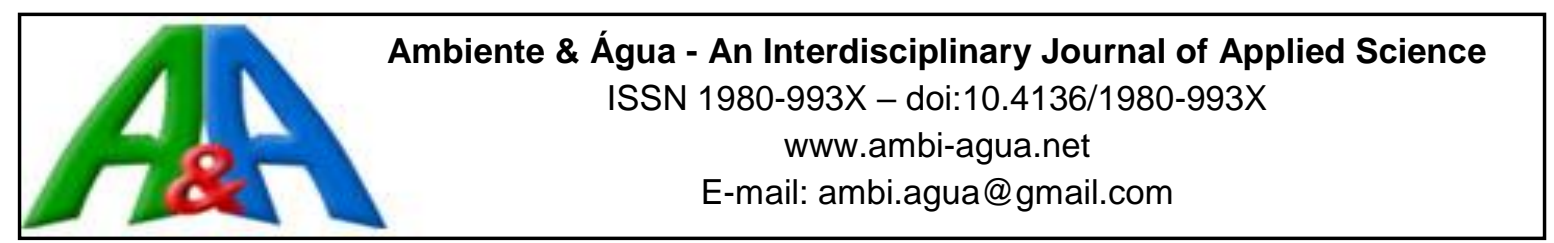

\title{
Composto de lodo de esgoto para o cultivo inicial de eucalipto
}

\author{
doi:10.4136/ambi-agua.1965
}

Received: 25 Jul. 2016; Accepted: 29 Oct. 2016

\author{
Daniela Cristina de Souza Afáz ${ }^{1}$; Kaique Bizon Bertolazi ${ }^{2}$; \\ Ricardo Augusto Gorne Viani ${ }^{2}$; Claudinei Fonseca Souza ${ }^{1 *}$ \\ Universidade Federal de São Carlos (UFSCar), Araras, SP. Brasil \\ ${ }^{1}$ Departamento de Recursos Naturais e Proteção Ambiental (DRNPA) \\ ${ }^{2}$ Departamento de Biotecnologia e Produção Vegetal e Animal (DBPVA) \\ *Autor correspondente: e-mail: cfsouza@cca.ufscar.br, \\ daniela.cr.souza@gmail.com,kbb7@hotmail.com,viani@cca.ufscar.br
}

\section{RESUMO}

Neste trabalho, foi avaliada a viabilidade do uso de composto de lodo de esgoto, proveniente de estação de tratamento de esgoto, como fertilizante alternativo para o cultivo inicial de eucalipto. O experimento foi realizado em casa de vegetação no CCA - UFSCar, Araras, SP. Os cultivos ocorreram em vasos de $11 \mathrm{~L}$ durante 75 dias. O delineamento experimental foi inteiramente ao acaso, com cinco tratamentos e sete repetições. Os tratamentos adotados foram constituídos por uma testemunha, três tratamentos com composto de lodo de esgoto $(25 \%, 50 \%$ e $75 \%$ do volume do vaso) e um tratamento com fertilizante mineral convencional, todos em solo arenoso. Ao final do experimento, a taxa de crescimento relativo (TCR) e a massa seca das plantas foram medidas e submetidas à análise de variância seguida pelo teste de Tukey a 5\% de probabilidade. A TCR foi maior nos tratamentos com fertilização do que na testemunha, mas não diferiu entre a fertilização mineral e as doses de fertilização orgânica. A massa seca das plantas foi maior no tratamento com $50 \%$ do volume do vaso com fertilizante orgânico $(\mathrm{p}<0,01)$. Assim, o composto de lodo de esgoto se mostrou com potencial para substituir fertilizantes minerais convencionais no cultivo inicial de eucalipto.

Palavras-chave: composto orgânico, fertilizante, nutrição vegetal,.orgânico classe D, sustentabilidade.

\section{Sewage sludge compost for initial cultivation of eucalyptus}

\begin{abstract}
This study evaluated the feasibility of sewage sludge compost obtained from a sewage treatment plant as an alternative "Class D" organic fertilizer for the initial cultivation eucalyptus. The experiment was conducted in a greenhouse at CCA - UFSCar, Araras, SP. Cultivation occurred in $11 \mathrm{~L}$ pots for 75 days. We adopted a completely randomized design, with five treatments and seven repetitions. The tests considered a control treatment with no fertilization, three treatments with sewage sludge compost addition $(25 \%, 50 \%$, and $75 \%$ of the pot volume) and a treatment with conventional mineral fertilizers, all in sandy soil. At the end of the experiment, plant relative growth rate and dry mass were evaluated and submitted to analysis of variance, followed by a Tukey test at 5\% probability. Treatments with
\end{abstract}


fertilization had a greater relative growth rate than the control; however, we found no difference between mineral and organic fertilization. Plant dry mass was higher in the treatment with $50 \%$ of the pot filled with organic fertilizer. Thus, we conclude that the tested sewage sludge compost is a potential substitute for conventional mineral fertilization for the initial cultivation of eucalyptus.

Keywords: class D organic fertilizer, organic compost, plant nutrition, sustainability.

\section{INTRODUÇÃO}

O lodo de esgoto é um resíduo rico em matéria orgânica, obtido ao final do processo de tratamento de águas servidas à população. A destinação adequada deste resíduo é necessária, devido aos problemas ambientais que podem ser ocasionados, principalmente com a contaminação do solo e da água. A deposição em aterros sanitários é uma destinação tida como segura, mas o alto custo da manutenção, que nem sempre é realizada adequadamente, pode não resolver problemas de contaminação do solo, ar e água (Quintana et al., 2011). Ou seja, há carência de formas seguras e eficazes de processamento e acondicionamento deste importante resíduo.

No Brasil, de acordo com o Sistema Nacional de Informações sobre Saneamento - SIS Diagnóstico de Serviço de Água e Esgoto 2014, o volume de esgoto tratado é de 3,8 bilhões de $\mathrm{m}^{3}$, correspondendo a 40,9\% da população que têm seu esgoto devidamente coletado e tratado. Este cenário é um desafio à destinação do resíduo orgânico, visto o grande volume gerado e o pequeno volume processado nos usos benéficos mais comuns ou de maior potencial: fabricação de cimento, disposição no solo, fabricação de tijolos e cerâmica e, também, aplicação para a melhoria da sedimentabilidade em águas de baixa turbidez, recuperação de coagulantes, controle de $\mathrm{H}_{2} \mathrm{~S}$, conversão em óleo combustível e recuperação de solos (Tsutiya, 2000; Rigo et al., 2014). Porém, ao mesmo tempo, esse cenário cria uma oportunidade a um dos potenciais destinos do lodo de esgoto, que é a agricultura. $\mathrm{Na}$ agricultura, há cada vez mais necessidade de se buscar fontes alternativas de fertilizantes que diminuam os custos de cultivos agrícolas e que tragam maiores opções aos produtores, adequando a exploração dos recursos naturais (Vaz e Gonçalves, 2002).

A aplicação de lodo de esgoto em cultivos agrícolas e também em áreas degradadas que precisam ser recuperadas tem sido o objeto de vários estudos (Caldeira Junior et al., 2009; Lobo et al., 2013; Bittencourt et al., 2014; Romeiro et al., 2014). De modo geral, os resultados têm sido positivos, destacando que o lodo fornece nutrientes e promove bom crescimento às plantas além de propiciar benefícios às propriedades físicas do solo (Rocha et al. 2004; Garcia et al., 2010; Bonini et al., 2015). O lodo é um condicionador do solo, que facilita a formação de agregados e, consequentemente, melhora a aeração, a infiltração e a retenção de água no solo, além de fornecer compostos orgânicos e nutrientes necessários para o desenvolvimento dos cultivos (Bonini e Alves, 2011).

Ao mesmo tempo em que o lodo de esgoto apresenta benefícios em seu uso agrícola, ele ocasiona riscos, pois o lodo pode apresentar quantidade elevada de metais pesados em sua composição, além de patógenos, vírus, protozoários e vermes, que podem contaminar o solo, o lençol freático e as plantas cultivadas (Soccol et al., 1997; Dores-Silva et al., 2011). Desse modo, sua aplicação direta na agricultura tem restrições.

Uma alternativa para a destinação do lodo de esgoto é a compostagem, que reduz os riscos e impactos ocasionados pela aplicação direta deste resíduo orgânico na agricultura. A compostagem é um processo biológico aeróbio de tratamento de resíduos orgânicos, que acelera a decomposição da matéria orgânica por micro-organismos e enzimas (Budziak et al., 2004). Durante o processo de compostagem, há elevação da temperatura e alterações na aeração, umidade, relação carbono:nitrogênio, teores de nutrientes e composição de 
micro-organismos da matéria prima. Estes fatores tendem a reduzir a presença de patógenos, parasitas e contaminantes no lodo de esgoto, tornando-o um produto mais seguro para uso na agricultura (Pereira et al., 2013).

Recentemente, fertilizantes passaram a ser produzidos comercialmente no Brasil a partir da compostagem do lodo de esgoto, gerando os compostos de lodo de esgoto, também chamados de fertilizantes orgânicos classe D. O fertilizante orgânico classe D é, de acordo com a Instrução Normativa $\mathrm{N}^{\mathrm{o}} 25$ de 23/07/2009 do Ministério da Agricultura, o fertilizante de origem orgânica que, em sua produção, utiliza-se de qualquer quantidade de matéria prima oriunda do tratamento de despejos sanitários, mas que resulta em produto de utilização segura na agricultura (Brasil, 2009), tendo empresas que comercializam e/ou distribuem estes compostos de lodo de esgoto.

Geralmente, estes compostos de lodo de esgoto têm como matéria prima não apenas o lodo de esgoto, mas resíduos diversos (restos de alimentos, resíduos de poda e corte de grama, etc.), adicionados durante o processo de compostagem. Mesmo sendo considerado seguro, há restrições de uso para o composto de lodo de esgoto: é proibido em pastagens, no cultivo de olerícolas, tubérculos e raízes, nas culturas inundadas e nas demais culturas cuja parte comestível entra em contato com o solo. Entretanto, este pode ser utilizado como fertilizante para espécies florestais destinadas à produção de madeira e celulose, por exemplo, tendo como potenciais vantagens a diminuição das descargas de lodo em aterros sanitários, incineradores, mares e corpos de água, a ciclagem dos nutrientes, o aporte de matéria orgânica no solo, e a possibilidade de redução de custos com o uso de fertilizantes minerais.

O eucalipto é amplamente cultivado no Brasil, ocupando mais de 5 milhões de ha e tendo um papel relevante para a economia do país (ABRAF, 2013). De modo geral, o eucalipto cresce rápido e responde a variações na fertilidade do solo (Mendes et al., 2013; Dias et al.; 2015). A adubação do eucalipto é realizada empregando-se geralmente fertilizantes minerais e, boa parte dos fertilizantes, é aplicada no momento do plantio (adubação de base), de modo a proporcionar o arranque das mudas no campo (Barros et al., 2000; Gonçalves, 2005). Portanto, há carência de estudos científicos com compostos de lodo de esgoto e, ao mesmo tempo, grande oferta deste produto e demanda de fertilizantes para a cultura do eucalipto. Desse modo, este estudo avaliou a viabilidade do uso de composto de lodo de esgoto (fertilizante orgânico classe D), proveniente de estação de tratamento, como fertilizante alternativo para a adubação na fase inicial do cultivo de eucalipto.

\section{MATERIAL E MÉTODOS}

O experimento foi conduzido em uma casa de vegetação do Departamento de Recursos Naturais e Proteção Ambiental (DRNPA) do CCA - UFSCar (Centro de Ciências Agrárias Universidade Federal de São Carlos), localizado em Araras, Estado de São Paulo, (22 $18 ' 22,4^{\prime \prime}$ S; $\left.47^{\circ} 23^{\prime} 11,1^{\prime \prime} \mathrm{O}\right)$. O clima da região é caracterizado por duas estações bem definidas, sendo uma seca, de abril a setembro, e outra chuvosa, de outubro a março, e enquadra-se no tipo "Cwa" de Köppen (Setzer, 1967), com uma precipitação média anual de $1300 \mathrm{~mm}$.

O estudo foi desenvolvido em casa de vegetação, composta por uma estrutura metálica do tipo teto em arco, com pé-direito de $3 \mathrm{~m}$, comprimento de $18 \mathrm{~m}$ e $6,4 \mathrm{~m}$ de largura, coberta com filme plástico transparente de 150 microns e com laterais fechadas por tela do tipo sombrite. O cultivo ocorreu de 12 de novembro de 2014 à 28 de janeiro de 2015, contabilizado 75 dias.

\subsection{Descrição do experimento}

O experimento foi composto por cinco tratamentos com sete repetições, totalizando 35 vasos, dispostos num delineamento inteiramente ao acaso (Figura 1). Os cinco tratamentos 
foram constituídos por: uma testemunha composta apenas por solo arenoso (T1), três tratamentos com 25\% (T2), 50\% (T3) e 75\% (T4) de composto de lodo de esgoto e um tratamento com adubação convencional (T5), todos em solo arenoso. As porcentagens foram fracionadas em $25 \%$ pela falta de fontes científicas para a recomendação da dosagem ideal para a cultura do eucalipto. Desta forma, também foi fonte de pesquisa a dosagem de melhor resposta.

O solo utilizado, pertencente ao grupo Neossolo Quartzarênico, foi coletado de uma camada superficial $(0-0,30 \mathrm{~m})$ na região de Leme, cujas coordenadas geográficas são: latitude $22^{\circ} 11^{\prime} 08^{\prime \prime}$ sul e longitude $47^{\circ} 23$ '25" oeste.

No experimento foi utilizado o composto de lodo de esgoto, proveniente da Estação de Tratamento de Esgoto - ETE Jundiaí (ETEJ), Jundiaí-SP, o qual utiliza o processo de lagoas aeradas de mistura completa, seguida de lagoa de decantação. O lodo de esgoto gerado pela ETEJ é compostado em sistema de Leiras Revolvidas (Sistema "Windrow"), a partir da sua mistura na proporção $1: 1 \mathrm{v} \mathrm{v}^{-1}$, com podas urbanas trituradas ou bagaço de cana-de-açúcar.

Mudas de eucalipto do hibrido urograndis (Eucalyptus urophylla $\mathrm{x}$ E. grandis), clone H13, foram obtidas no Instituto de Pesquisas e Estudos Florestais - IPEF, Piracicaba - SP. A escolha do eucalipto foi baseada na sua resposta rápida ao uso de fertilizantes, e também pelo fato de serem mudas clonadas, o que elimina a variabilidade genética como fonte de variação nos resultados.

As mudas foram transplantadas para vasos com dimensões de $0,24 \mathrm{~m}$ de diâmetro e 0,18 $\mathrm{m}$ de altura, com um volume de $11 \mathrm{~L}$. Para a preparação dos vasos, inicialmente foi acrescentado $1,5 \mathrm{~kg}$ de pedra tipo brita, em seguida um tecido geotêxtil (cuja finalidade foi de evitar a perda de solo pela drenagem) e, por fim, $8 \mathrm{~kg}$ de TFSA (terra fina seca ao ar) passada em peneira de $2 \mathrm{~mm}$, até atingir $2 \mathrm{~cm}$ da borda. Os vasos possuíam drenos na lateral inferior para retirar o excesso de água do solo.

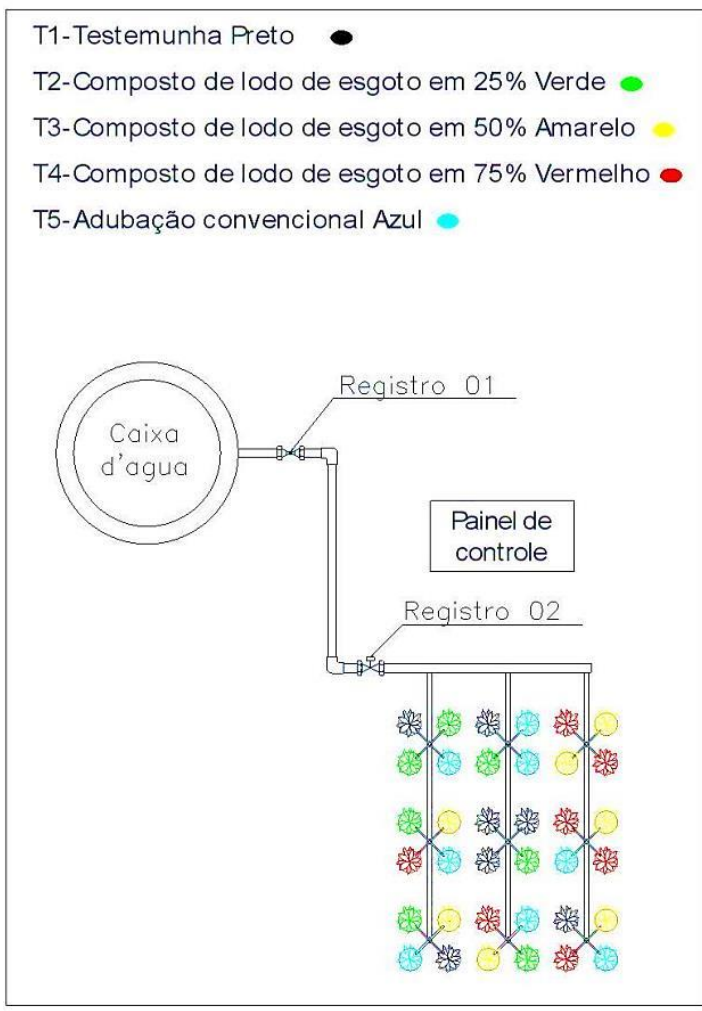

Figura 1. Distribuição ao acaso dos tratamentos avaliados dentro da casa de vegetação. 
No T5, foi realizada adubação com $36 \mathrm{~g}$ de N, $24 \mathrm{~g}$ de $\mathrm{P}_{2} \mathrm{O}_{5}$ e $30 \mathrm{~g}$ de $\mathrm{K}_{2} \mathrm{O}$ por vaso, que foram fornecidos através de $48 \mathrm{~g}$ de mono-amônio-fosfato $\left(50 \%\right.$ de $\mathrm{P}_{2} \mathrm{O}_{5}$ e $10 \%$ de $\mathrm{N}$ ), $68 \mathrm{~g}$ de nitrato de potássio $\left(44 \%\right.$ de $\mathrm{K}_{2} \mathrm{O}$ e $13 \%$ de $\left.\mathrm{N}\right)$ e $163 \mathrm{~g}$ de nitrato de cálcio $(15 \%$ de $\mathrm{N})$ por vaso. Esta adubação foi definida com base na análise do solo arenoso, seguindo as recomendações de fertilização do IPEF (Gonçalves, 2005). Porém, como essa recomendação é dada pela área, foi necessário dividir a quantidade de fertilizante demandado por hectare, pelo número de plantas existente num hectare, no espaçamento convencional de cultivo (1.667 plantas, espaçamento $3 \times 2 \mathrm{~m}$ ).

Os fertilizantes foram aplicados em cova no momento do transplantio, sendo a única adubação realizada no cultivo. O sistema de irrigação foi instalado com uma vazão de $1 \mathrm{~L} \mathrm{~h}^{-1}$ por vaso, o qual era acionado quatro vezes ao dia, com duração de 10 minutos por vez, aproximadamente com uma lamina de água de $3,7 \mathrm{~mm} \mathrm{dia}^{-1}$.

\subsection{Caracterização química do composto de lodo de esgoto}

A caracterização química (macro e micronutrientes, matéria orgânica e capacidade de troca catiônica - CTC) do composto de lodo de esgoto utilizado foi realizada no Laboratório de Química e Nutrição dos Solos do Centro de Ciências Agrárias, da UFSCar, seguindo os métodos estabelecidos para solos por Van Raij et al. (1997). Ressalta-se que estes métodos foram originalmente estabelecidos para solos, mas têm sido usados para a caracterização do lodo, em virtude da ausência de métodos de análise mais específicos para este tipo de material.

Foram coletadas cinco amostras de $10 \mathrm{~g}$ de composto de lodo de esgoto, as quais compuseram uma única amostra composta.

\subsection{Análise de micro-organismos patogênicos}

Foram feitas análises iniciais no composto para verificar a presença de micro-organismos patogênicos, por meio da coleta de duas amostras de $10 \mathrm{~g}$, encaminhadas para o Laboratório de Microbiologia Aplicada da UFSCar. Foram avaliadas a presença dos micro-organismos coliformes totais e termotolerantes (Escherichia coli), as quais são usadas como indicadoras de contaminação por fezes humanas, sendo E. coli uma bactéria presente no trato intestinal de animais de sangue quente.

Foi adotada a metodologia das placas Petrifilm da $3 \mathrm{M}^{1}$ para coliformes totais e E. coli. As amostras para a análise microbiológica foram manipuladas em câmara de fluxo laminar em solução de peptona $0,1 \%$, sendo posteriormente inoculadas nas placas Petrifilm. Após o período de incubação de 24 e $48 \mathrm{~h}$, procedeu-se a contagem de coliformes totais e $E$. coli, respectivamente.

\subsection{Análises do crescimento do eucalipto}

Para alcançar o objetivo de avaliar o crescimento das plantas ao longo do tempo experimental, avaliou-se, ao final do experimento, a matéria seca das plantas. Além disso, foi mensurada a taxa de crescimento relativo (TCR), usando a Equação 1 (Benincasa, 2003).

$$
\operatorname{TCR}\left(\frac{g / g}{\text { dias }}\right)=\frac{(\ln \mathrm{M} 2-\ln \mathrm{M} 1)}{(\mathrm{P} 2-\mathrm{P} 1)}
$$

em que:

M1 - massa seca total inicial;

M2 - massa seca total final;

\footnotetext{
${ }^{1}$ Referências à marca registrada não constituem endosso por parte dos autores.
} 
$(\mathrm{P} 2-\mathrm{P} 1)$ - intervalo em dias do início ao final do experimento.

Para as medidas de TCR, foram avaliadas, no início do experimento, no momento do plantio, 10 mudas de eucalipto não utilizadas. Para a análise da matéria seca, as plantas foram secas em estufa de circulação de ar a $60^{\circ} \mathrm{C}$ durante $48 \mathrm{~h}$.

\subsection{Análise estatística dos dados}

Os dados de massa seca e TCR das plantas foram submetidos à análise de variância utilizando o programa Assistat 7.6 Beta (Silva e Azevedo, 2009). Quando a ANOVA foi significativa, as médias dos tratamentos foram comparadas entre si usando o teste de Tukey $(\mathrm{p}<0,05)$.

\section{RESULTADOS E DISCUSSÃO}

\subsection{Caracterização química e microbiológica}

O composto de lodo de esgoto avaliado apresentou $49 \%$ de matéria orgânica e uma alta CTC (Tabela 1). Os compostos nutricionais com maiores teores em sua composição foram óxido de cálcio e sulfato, seguidos pelo pentóxido de fósforo. Moretti et al. (2015) encontraram valores de grandeza semelhantes para composto de lodo de esgoto, na ordem de 18,12 e $3 \mathrm{~g} \mathrm{~kg}^{-1}$ para NPK e 21, 3 e $5 \mathrm{~g} \mathrm{~kg}^{-1}$ para Ca, Mg e S. Entretanto, os resultados são discrepantes para $\mathrm{K}$ e $\mathrm{S}$, os quais podem ser explicados devido à sazonalidade na composição física, química e biológica do esgoto bruto.

\begin{tabular}{lc}
$\begin{array}{l}\text { Tabela 1. Caracterização } \\
\text { microbiológica do composto de lodo de esgoto }\end{array}$ \\
$\begin{array}{l}\text { utilizado em experimento com cultivo de } \\
\text { eucalipto. }\end{array}$ \\
\hline \multicolumn{1}{c}{ Parâmetros } & Valor \\
\hline $\mathrm{pH}$ & 7,4 \\
Matéria orgânica $\left(\mathrm{g} \mathrm{kg}^{-1}\right)$ & 490 \\
Carbono $\left(\mathrm{g} \mathrm{kg}^{-1}\right)$ & 282 \\
Nitrogênio $\left(\mathrm{g} \mathrm{kg}^{-1}\right)$ & 17 \\
Pentóxido de fósforo $\left(\mathrm{g} \mathrm{kg}^{-1}\right)$ & 25,4 \\
Oxido de potássio $\left(\mathrm{g} \mathrm{kg}^{-1}\right)$ & 15 \\
Óxido de cálcio $\left(\mathrm{g} \mathrm{kg}^{-1}\right)$ & 26,2 \\
Óxido de magnésio $\left(\mathrm{g} \mathrm{kg}^{-1}\right)$ & 5,2 \\
Sulfato $\left(\mathrm{g} \mathrm{kg}^{-1}\right)$ & 26,2 \\
Cobre $\left(\mathrm{g} \mathrm{kg}^{-1}\right)$ & 0,6 \\
Ferro $\left(\mathrm{g} \mathrm{kg}^{-1}\right)$ & 2,3 \\
Manganês $\left(\mathrm{g} \mathrm{kg}^{-1}\right)$ & 0,5 \\
Zinco $\left(\mathrm{g} \mathrm{kg}^{-1}\right)$ & 1,3 \\
CTC $\left(\mathrm{mmolc} \mathrm{kg}^{-1}\right)$ & 240 \\
Coliformes totais & $>10^{-3}$ \\
Coliformes termotolerantes & Ausentes \\
\hline
\end{tabular}

Os coliformes termotolerantes (Escherichia coli) foram ausentes no fertilizante orgânico e, para coliformes totais $>10^{3} \mathrm{UFC} / \mathrm{g}$ (Tabela 1). Portanto, de acordo com as análises, o processo de compostagem provavelmente permitiu a inativação de coliformes termotolerantes presentes no lodo. O mesmo resultado pode ser observado por Rocha et al. (2013), que não 
encontraram coliformes termotolerantes quando avaliaram composto de lodo de esgoto como componente de substrato para produção de mudas clonais de eucalipto.

\subsection{Taxa de crescimento relativo e massa seca}

A TCR não diferiu quando comparados os tratamentos com o composto de lodo de esgoto e o fertilizante convencional, porém a testemunha sem fertilização apresentou uma menor TCR (Tabela 2, Figura 2). Estes resultados indicam que as taxas de crescimento do eucalipto não foram diferentes em função da fonte orgânica ou mineral dos fertilizantes, sugerindo que o composto de lodo de esgoto testado poderia substituir o fertilizante mineral convencional. Ademais, corroboram os resultados de Vaz e Gonçalves (2002), que também observaram uma igualdade no desenvolvimento de plantas de eucalipto fertilizadas com biossólido e fertilizantes minerais.

Tabela 2. Análise de variância da taxa de crescimento relativo ao final do período em casa de vegetação das plantas de eucalipto de cada tratamento (g $\left.\mathrm{g}^{-1} \mathrm{p}\right)$.

\begin{tabular}{lcccc}
\hline Causas de Variação & GL & SQ & QM & F \\
\hline Tratamentos & 4 & 3,16 & 0,79 & $16,11^{* *}$ \\
Resíduo & 30 & 1,47 & 0,05 & \\
\hline Total & $\mathbf{3 4}$ & $\mathbf{4 , 6 3}$ & & \\
\hline
\end{tabular}

** significativo ao nível de $1 \%$ de probabilidade ( $>>0,01)$; ns: não significativo ( $\mathrm{p} \geq 0,05)$; GL: grau liberdade; $\mathbf{S Q}$ : soma de quadrados; $\mathbf{Q M}$ : quadrado médio; e $\mathbf{F}$ : estatística do teste F.

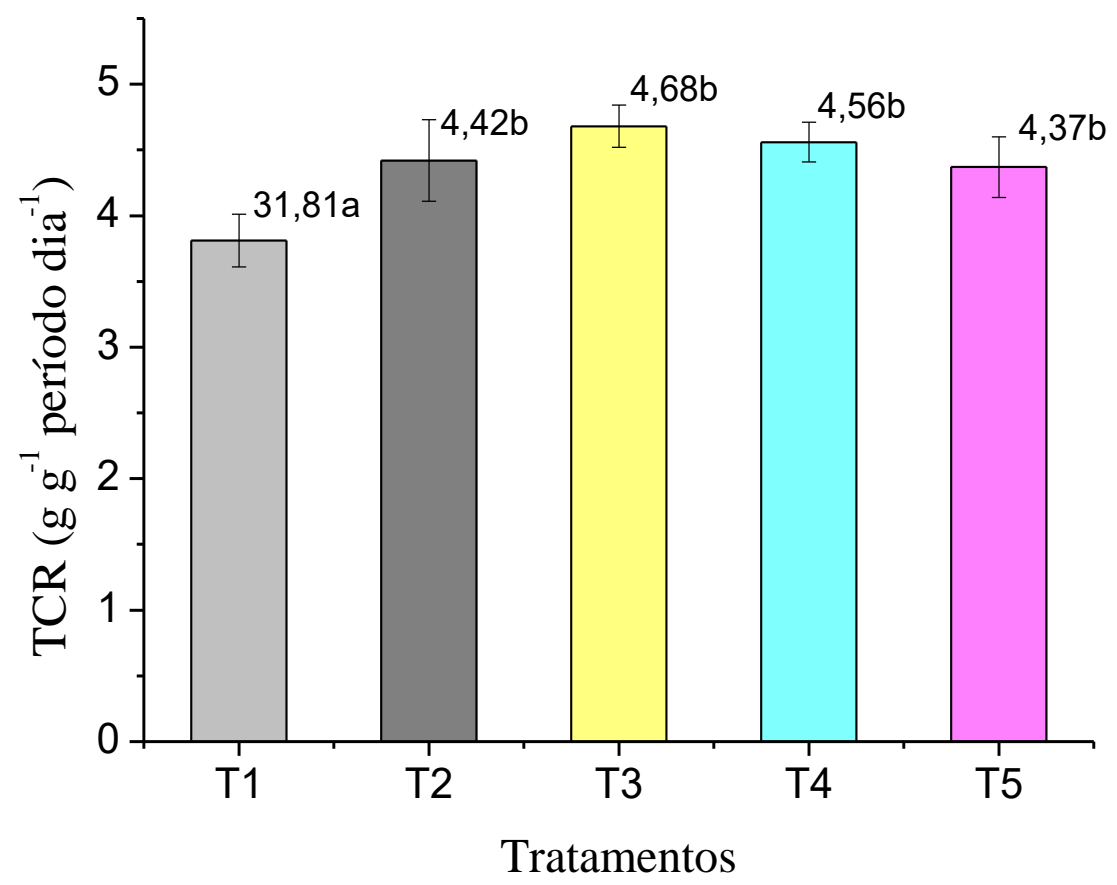

Figura 2. Resultados médios da Taxa de Crescimento Relativo ( $\mathrm{g} \mathrm{g}^{-1}$ período) após 75 dias de cultivo em casa de vegetação, para mudas de eucalipto submetidas a diferentes doses de composto de lodo de esgoto. Barras com letras diferentes diferem entre si (teste de Tukey, $\mathrm{p}<0,05)$. T1: testemunha em solo arenoso, T2: $25 \%$ de fertilizante orgânico; T3: 50\% de fertilizante orgânico; T4: $75 \%$ de fertilizante orgânico; T5: adubação mineral convencional. 
No entanto, os tratamentos diferiram entre si em relação ao acúmulo de massa seca (Tabela 3). Plantas do T3 (50\% de fertilizante orgânico) acumularam mais massa seca que plantas dos demais tratamentos com fertilização, os quais foram superiores à testemunha (Figura 3). Estes resultados corroboram parcialmente com os observados por Garcia et al. (2010), que também verificaram um incremento da massa seca e da TCR de eucalipto cultivado em ambiente protegido, Porém, diferentemente deste estudo, os resultados observados por Garcia et al. (2010) foram com aplicação de lodo de esgoto e com as maiores doses do fertilizante orgânico, proporcionando os maiores valores de TCR e massa seca no eucalipto.

Tabela 3. Análise de variância da matéria seca total das plantas de eucalipto de cada tratamento ( $\mathrm{g}$ planta ${ }^{-1}$ ) ao final do período em casa de vegetação.

\begin{tabular}{lcccc}
\hline Causas de Variação & GL & SQ & QM & F \\
\hline Tratamentos & 4 & 16745,21 & 4186,3 & $12,72 * *$ \\
\hline Resíduo & 30 & 9869,04 & 328,96 & \\
\hline Total & 34 & 26614,25 \\
** significativo ao nível de 1\% de probabilidade (p>0,01); ns: não significativo \\
(p $\geq 0$,05); GL: grau liberdade; SQ: soma de quadrados; QM: quadrado médio; \\
F: estatística do teste F.
\end{tabular}

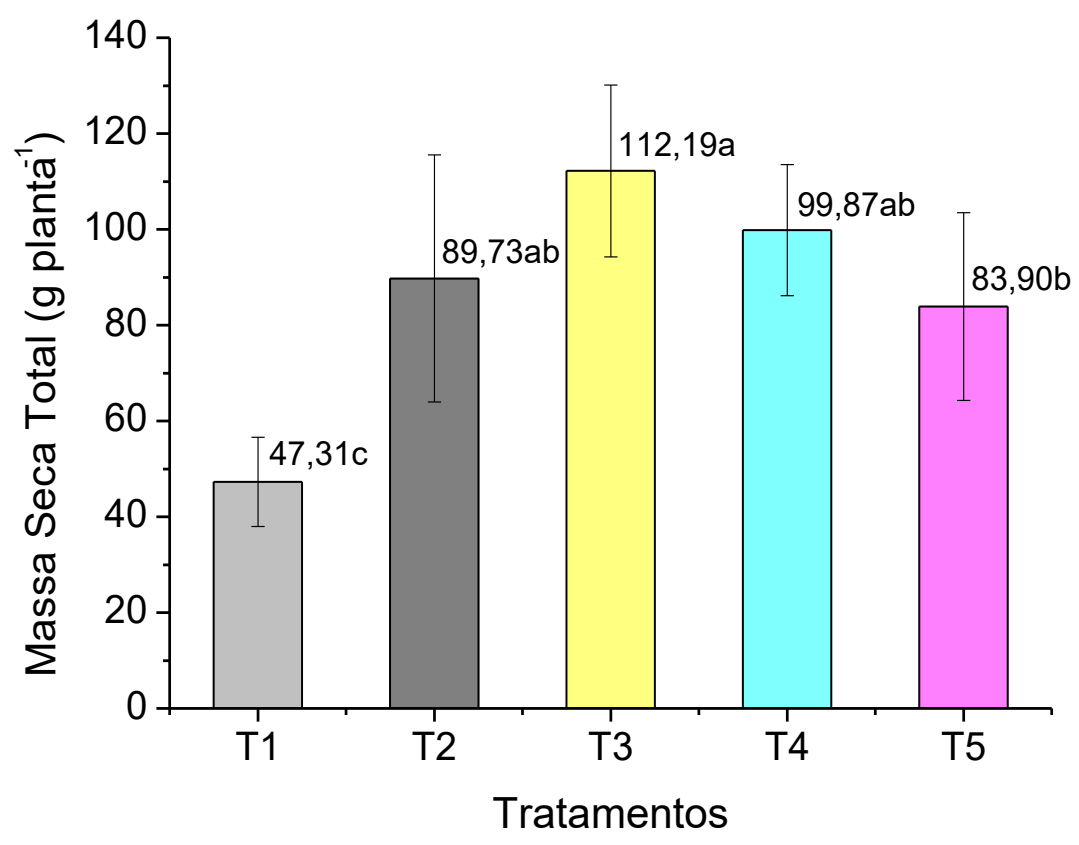

Figura 3. Resultados médios da Massa Seca Total $\left(\mathrm{g}\right.$ planta $\left.{ }^{-1}\right)$ após 75 dias de cultivo em casa de vegetação, para mudas de eucalipto submetidas a diferentes doses de composto de lodo de esgoto. Barras com letras diferentes diferem entre si (teste de Tukey, $\mathrm{p}<0,05)$. T1: testemunha em solo arenoso, T2: $25 \%$ de fertilizante orgânico; T3: 50\% de fertilizante orgânico; T4: 75\% de fertilizante orgânico; T5: adubação mineral convencional.

O incremento na massa seca com a fertilização orgânica se deve a um aumento de nutrientes no solo seguido de um efeito de melhoria da estrutura que a matéria orgânica 
promove (Costa et al., 2001). Esse efeito causa um aumento na CTC do solo, em função das cargas negativas da matéria orgânica, ampliando o "reservatório nutricional" do solo. Outro benefício é o aumento da taxa de microporosidade do solo, aumentando a retenção de água no mesmo. Além disso, a matéria orgânica introduz no sistema micronutrientes que geralmente não são fornecidos através da fertilização mineral concentrada em NPK. Rocha et al. (2004), pesquisando as alterações de fertilidade no solo e desenvolvimento de um povoamento de Eucalyptus grandis adubado com biossólido, verificaram que os tratamentos com fertilizante orgânico foram superiores ao tratamento com fertilizantes minerais, assim obtendo resultados ainda mais evidentes dos incrementos no desenvolvimento das plantas adubadas com fertilizantes orgânicos.

Diante destas constatações, era esperado que o tratamento $\mathrm{T} 4$ (75\% de fertilizante orgânico), com maiores doses do fertilizante orgânico, proporcionasse o maior acúmulo de massa seca nas plantas de eucalipto. Entretanto, foi encontrada maior massa seca com um tratamento intermediário quanto à adição de matéria orgânica. Investigações futuras são necessárias para compreender quais alterações ocasionaram um decréscimo na massa seca quando doses maiores do composto de lodo de esgoto foram adicionadas, algo não observado com eucalipto em outros experimentos realizados com o lodo aplicado in natura (Rocha et al. 2004; Garcia et al., 2010).

\section{CONCLUSÃO}

Com os resultados deste trabalho é possível concluir que, nas condições experimentais, a aplicação de composto de lodo de esgoto promoveu desenvolvimento inicial satisfatório das plantas de eucalipto, não havendo prejuízo em termos de acúmulo de matéria seca, taxa de crescimento ou acúmulo de nutrientes nas folhas.

A TCR não apresentou diferença significativa nos cultivos com composto de lodo de esgoto e convencional (adubação mineral), revelando que o uso do composto de lodo de esgoto ou convencional proporcionam desenvolvimento inicial semelhante das plantas de eucalipto. Já a matéria seca das plantas foi maior com a adição de $50 \%$ de fertilizante orgânico no solo de cultivo do que com a fertilização mineral. Portanto, o composto de lodo de esgoto poderia ser utilizado em substituição ao fertilizante mineral, no cultivo do eucalipto.

\section{AGRADECIMENTOS}

Ao CCA/UFSCar, PPGAA, CAPES, EASA, Tera Ambiental e IPEF.

\section{REFERÊNCIAS}

ASSOCIAÇÃO BRASILEIRA DE PRODUTORES DE FLORESTAS PLANTADAS ABRAF. Anuário Estatístico da ABRAF 2013: ano base 2012. Brasília, 2013. 146p.

BARROS, N. F.; NEVES, J. C. L.; NOVAIS, R. F. Recomendação de fertilizantes minerais em plantios de eucalipto. In: GONÇALVES, J. L. de M.; BENEDETTI, V. (Eds.). Nutrição e fertilização florestal. Piracicaba: IPEF, 2000. p. 269-286.

BENINCASA, M. M. P. Análise de crescimento de plantas: (noções básicas. Jaboticabal: FUNEP, 2003. 42p. 
BITTENCOURT, S.; SERRAT, B. M.; AISSE, M. M.; GOMES, D. Sewage Sludge Usage in agriculture: a case study of its destination in the Curitiba metropolitan region, Paraná, Brazil. Water, Air \& Soil Pollution, v. 225, p. 1-8, 2014. http://dx.doi.org/10.1007/s11270-014-2074-y

BONINI, C. S. B; ALVES, M. C.; MONTANARI, R. Lodo de esgoto e adubação mineral na recuperação de atributos químicos de solo degradado. Revista Brasileira de Engenharia Agrícola e Ambiental, v. 19, n. 4, p.388-393, 2015. http://dx.doi.org/10.1590/1807-1929/agriambi.v19n4p388-393

BONINI, C. S. B.; ALVES, M. C. Estabilidade de agregados de um Latossolo vermelho degradado em recuperação com adubos verdes, calcário e gesso. Revista Brasileira de Ciência do Solo, v. 35, n. 4, p. 1263-1270, 2011. http://dx.doi.org/10.1590/S010006832011000400019

BRASIL. Ministério da Agricultura e Abastecimento - MAPA. Instrução Normativa $\mathrm{n}^{\circ}$ 25, de 23 de julho de 2009. Aprova as Normas sobre as especificações e as garantias, as tolerâncias, o registro, a embalagem e a rotulagem dos fertilizantes orgânicos simples, mistos, compostos, organominerais e biofertilizantes destinados à agricultura. Diário Oficial [da] União, Brasília, DF, 28 de julho de 2009. Seção 1, p. 20.

BUDZIAK, C. R.; MAIA, C. M. B. F.; MANGRICH, A. S. Transformações químicas da matéria orgânica durante a compostagem de resíduos da indústria madeireira. Química Nova, v. 27, v. 3, p. 399-403, 2004. http://dx.doi.org/10.1590/S010040422004000300007

CALDEIRA JUNIOR, C. F.; SOUZA, R. A.; SANTOS, A. M.; SAMPAIO, R. A.; MARTINS, E. R. Características químicas do solo e crescimento de Astronium fraxinifolium Schott em área degradada adubada com lodo de esgoto e silicato de cálcio. Revista Ceres, v. 56, p. 213-218, 2009.

COSTA, A. N.; COSTA, A. F. S.; MARQUES, M. O.; SANTANA, R. C. Estudo de caso utilização de lodo de estações de tratamento de esgoto (ETEs) na cultura do mamoeiro no Norte do Estado do Espírito Santo. In: ANDREOLI, V. (Coord.). Resíduos sólidos do saneamento: processamento, reciclagem e disposição final. Rio de Janeiro: RiMa/ABES, 2001. p. 189-214.

DIAS, L. P. R.; GATIBONI, L. C.; BRUNETTO, G.; SIMONETE, M. A.; BICARATTO, B. Eficiência relativa de fosfatos naturais na adubação de plantio de mudas de Eucalyptus dunnii Maiden e Eucalyptus benthamii Maiden et Cambage em solo sem e com calagem. Ciência Florestal, v. 25, n. 1, p. 37-48, 2015. http://dx.doi.org/10. 5902/1980509817443

DORES-SILVA, P. R.; LANDGRAF, M. D.; REZENDE, M. O. Acompanhamento químico da vermicompostagem de lodo de esgoto doméstico. Química Nova, v. 34, n. 6, p. 956981, 2011. http://dx.doi.org/10.1590/S0100-40422011000600008

GARCIA, G. O.; GONÇALVES, I. Z.; MADALÃO, J. C.; NAZÁRIO, A. A.; REIS, E. F. Crescimento de mudas de eucalipto submetidas à aplicação de biossólidos. Ciência Agronômica, v. 41, n. 1, p. 87-94, 2010.

GONÇALVES, J. L. M. Recomendações de adubação para eucalyptus, pinus e espécies nativas. 2005. Disponível em: http://www.ipef.br/silvicultura/adubacao.asp. Acesso em: jul. 2016. 
LOBO, T. F., GRASSI FILHO, H.; BULL, L. T.; KUMMER, A. C. B. Efeito do lodo de esgoto e do nitrogênio nos fatores produtivos do girassol. Revista Brasileira de Engenharia Agrícola e Ambiental, v. 17, p. 504-509, 2013. http://dx.doi.org/ 10.1590/S1415-43662013000500006

MENDES, H. S. J.; PAULA, N. F.; SCARPINATTI, E. A.; PAUlA, R. C. Respostas fisiológicas de genótipos de Eucalyptus grandis x E. urophylla à disponibilidade hídrica e adubação potássica. Cerne, v. 19, n. 4, p. 603-611, 2013. http://dx.doi.org/10.1590/S0104-77602013000400010

MORETTI, S. M. L.; BERTONCINI, E. I.; ABREU-JUNIOR, C. H. Composting sewage sludge with green waste from tree pruning. Scientia Agricola, v. 72, p. 432-439, 2015. http://dx.doi.org/10.1590/0103-9016-2014-0341

PEREIRA, D. C.; WILSEN NETO, A.; NÓBREGA, L. H. Adubação orgânica e algumas aplicações agrícolas. Varia Scientia Agrárias, v. 3, n. 2, p. 159-174, 2013.

QUINTANA, N. R. G.; CARMO, M. S., MELO, W. J. Lodo de esgoto como fertilizante: produtividade agrícola e rentabilidade econômica. Nucleus, v. 8, n. 1, p. 183-912, 2011 http://dx.doi.org/10.3738/nucleus.v8i1.527

RIGO, M. M.; RAMOS, R. R.; CERQUEIRA, A. A.; SOUZA, P. S. A.; MARQUES, M. R. C. Destinação e reuso na agricultura do lodo de esgoto derivado do tratamento de águas residuária domésticas no Brasil. Gaia Scientia, v. 8, n. 1, p. 174-186, 2014.

ROCHA, G. N.; GONÇALVES, J. L. M.; MOURA, I. M. Mudanças da fertilidade do solo e crescimento de um povoamento de Eucalyptus grandis fertilizado com biossólido. Revista Brasileira de Ciência do Solo, v. 28, n. 4, p. 623-639, 2004. http://dx.doi.org/10.1590/S0100-06832004000400005

ROCHA, J. H. T.; BACKES, C.; DIOGO, F. A.; PASCOTTO, C. B.; BORELLI, K. Composto de lodo de esgoto como substrato para mudas de eucalipto. Pesquisa Florestal Brasileira, v. 33, n. 73, p. 27-35, 2013.

ROMEIRO, J. C. T.; GRASSI FILHO, H.; MOREIRA, L. L. Q. Absorção de N, P, K, CA e $\mathrm{Mg}$ por laranjeiras 'pêra' fertilizadas com lodo de esgoto compostado em substituição à adubação nitrogenada mineral. Irriga, v. 19, n. 1, p. 82-93, 2014.

SETZER, J. Atlas climático e ecológico do Estado de São Paulo. São Paulo: Comissão interestadual da Bacia Paraná-Uruguai, 1967.

SILVA, F. A. S.; AZEVEDO, C. A. V. Principal components analysis in the software assistant-statistical. In: WORLD CONGRESS ON COMPUTERS IN AGRICULTURE, 7., 2009, Reno. Proceedings... St. Joseph: ASABE, 2009.

SOCCOL, V. T.; PAULINO, R. C.; CASTRO, E. A.; TRACZ, J. Eficácia dos diferentes processos de tratamento do lodo na redução da viabilidade de ovos de helmintos. Sanare, v. 8, n. 8, p. 24-32, 1997.

TSUTIYA, M. T. Alternativas de disposição final de biossólidos gerados em estações de tratamento de esgotos. In: BETTIOL, W.; CAMARGO, O. A. (Eds.). Impacto ambiental do uso agrícola do lodo de esgoto. Jaguariúna: EMBRAPA Meio Ambiente, 2000. p. 69-105. 
Van RAIJ, B.; CANTARElla, J. A.; QUAGGiO, J. A.; FURLANI, A. M. C. Recomendações de adubação e calagem para o Estado de São Paulo. Campinas: Instituto Agronômico, 1997. 285p. (Boletim técnico, 10).

VAZ, L. M. S; GONÇALVES, J. L. M. Uso de biossólidos em povoamento de eucalipto: efeito em atributos químicos do solo, no crescimento e na absorção de nutrientes. Revista Brasileira de Ciência do Solo, v. 26, n. 3, p. 747-758, 2002. http://dx.doi.org/10.1590/S0100-06832002000300020 